\title{
Nickel Coated Carbon Nanomaterial for the Removal of Heavy and Toxic Metals (Cd, $\mathrm{Cu}$ ) from Water and Wastewater
}

\author{
TAYYABA Asim ${ }^{1, a^{*}}$, RIAZ Ahmed ${ }^{1, b}$ and MUHAMMAD Shahid Ansari ${ }^{1, c}$ \\ ${ }^{1}$ Department of Chemistry, Quaid-i-Azam University Islamabad, Pakistan \\ ${ }^{2}$ Quetta Institute of Medical Sciences, Quetta, Pakistan \\ *atayyabasim2008@gmail.com, briaz_ecfc@yahoo.com, cansari.shahid.m@gmail.com
}

\begin{abstract}
Keywords: Nickel Coated Carbon, Waste Water, Heavy Metals, Adsorption Energy.
\end{abstract}
\begin{abstract}
Heavy metals in water have always remained a point of concern for the environmental scientists due to their non biodegradability and toxicity. Adsorption and membrane filtration are the most widely studied and applied processes for the treatment of water. Activated carbons have frequently been used for the removal of heavy metals from water by the process of adsorption. With the development of nanotechnology, nanomaterials are used as the adsorbents in water treatment and have proved effective for the removal of heavy and toxic metals from water. Nanocarbon materials, nano-metal particles and polymer supported nanoparticles are widely used. A new adsorbent comprising of graphite coated with nano nickel particles was prepared, characterized and used for the removal of heavy and toxic metals from water. Nano material was characterized using ICP-AES, FTIR, XRD, and SEM. It was used for the removal of cadmium and copper from water and compared with carbon alone. Kinetics and thermodynamics of adsorption of cadmium and copper on both the materials was investigated and compared. Adsorption isotherm of Langmuir, Freundlich and Dubinin-Radushkevich were also applied to the adsorption data for the adsorption and removal of cadmium and copper. Effect of $\mathrm{pH}$ was also studied and it was found that nanomaterial was very effective for the removal of $\mathrm{Cd}$ and $\mathrm{Cu}$ from acidic solutions. Effect of different acids at different concentration was studied and it was found that nanomaterial remained stable for adsorption while carbon alone deteriorated. Results indicate that developed nanomaterial is a very effective adsorbent for the removal of heavy and toxic metals from water and wastewater.
\end{abstract}

\section{Introduction}

Heavy metals have gained their importance as non-biodegradable pollutants and this significance is increasing due to various nutritional, environmental and ecological reasons [1]. To name a few, the cadmium, copper, arsenic, lead and nickel pose great risk to the environment and living beings [2]. Copper appears in several enzymes within the living body, helps the absorption of iron, and facilitates in transmitting electrical signals in the body [3]. In high doses, however, copper can also saturate the water and soil, posing risks not only to the humans but to the wildlife also [4]. Due to various human activities such as combustion of ores, burning and use of fossil fuels, cadmium considerably exists in the environment and long-term exposure to cadmium can cause cancer and organ system toxicity such as skeletal, urinary, reproductive, cardiovascular, central and peripheral nervous and respiratory systems [5]. Presence of the heavy metals in water ensure that they will directly or indirectly become a part of the food chain. In order to remove these metals from the aquatic environment, many processes have been opted by the scientists however adsorption has proven to be the best and cost effective. Various carbon based adsorbents and catalysts have been prepared owing to their greater efficiency [6]. Since the advancement of nanotechnology has taken over almost all the fields of science and engineering, therefore carbon based adsorbents in combination with nano technology have also gained importance. Nano nickel coated carbon has been prepared by our previously reported method and characterized by using Xray diffraction (XRD), Fourier transformed infrared spectroscopy (FTIR), inductively coupled plasma-Atomic emission spectroscopy (ICP-AES) and scanning electron microscopy (SEM) [7]. This research has specially been designed to work out the possibility of using such an adsorbent 
which could not only adsorb copper and cadmium from the aquatic environment but also will not be deteriorated under rigorous conditions of $\mathrm{pH}$ and acid content. Various parameters for the sorption of cadmium and copper over nano nickel coated carbon have been optimized, the data is applied on the adsorption isotherms to find out the adsorption energies for both metals and the adsorption capacity of the adsorbent. Kinetic and thermodynamic parameters have also been evaluated subsequently.

\section{Experimental}

Reagents and Equipment. Analytical grade chemicals are used for making various $\mathrm{pH}$ solutions and different concentrations of acids. 100 mesh size graphite powder having surface area of $11.35 \mathrm{~m}^{2} . \mathrm{g}^{-1}$ is used for synthesizing nano nickel coated carbon.

For ICP-AES analysis, model 6500 instrument from Thermo-Fischer Scientific, U.K has been used XRD patterns are recorded on a 3040/60 X'Pert PRO X-ray diffractometer (Netherlands). FTIR spectrophotometer (Bio Rad Merlin FTS $3000 \mathrm{MX}$ ) is used. SEM used is Leo 440i (Cambridge, UK).

Adsorption Procedure. A known volume of the $\mathrm{Cu}$ (II) and Cd (II) ions stock solution was diluted with $10 \mathrm{ml}$ of doubly de-ionized water and the resulting solution agitated with a fixed amount of solvent $(100 \mathrm{mg})$ on a Stuart mechanical shaker at 700 RPM for a specific time to effect calibration. The resulting mixture was then centrifuged at $5000 \mathrm{rpm}$ to obtain phase separation. A portion of the supernatant solution was withdrawn and the $\mathrm{Cu}$ (II) and $\mathrm{Cd}$ (II) ions concentration measured by Atomic absorption spectrophotometer to establish the equilibrium concentration $(\mathrm{Ce})$. The initial concentration of $\mathrm{Cu}$ (II) and $\mathrm{Cd}$ (II) ions $\left(\mathrm{C}_{0}\right)$ is also measured by the same method. Distribution co-efficients $\left(\mathrm{R}_{\mathrm{d}}\right)$ is calculated as under:

$$
R_{d}=\frac{\text { Amount of metal on adsorbent }}{\text { Amount of metal in solution }} \times \frac{\text { Volume of solution }((V))}{\text { Weight of dry adsorbent }(w)} \mathrm{cm}^{3} / \mathrm{g}
$$

\section{Result and Discussion}

Characterization of the Adsorbent. Nickel coating as determined from the ICP-AES analysis for the adsorbent comes out to be $2.85 \pm 0.03 \%$ closer to the expected value of almost $3 \%$. From the XRD of nano nickel coated carbon (Fig. 1) the crystallite size of the deposited nickel was determined as about $9 \mathrm{~nm}$ [7]. Various spectral changes have been observed for the nano nickel coated carbon; these being appearance of a broadband (free and hydrogen bonded $\mathrm{OH}$ groups) between 2900 and $3600 \mathrm{~cm}^{-1}$, peaks around $1610 \mathrm{~cm}^{-1}\left(\mathrm{C}=\mathrm{O}\right.$ group) and from 1180 to $1350 \mathrm{~cm}^{-1}$ (C$\mathrm{O}$ of carboxylic group) respectively. Creation of hydroxyl group peaks after the deposition of nickel creates functional groups which can attach more toxic metals thereby increasing adsorption.

SEM micrographs have shown morphological changes (breaking down) undergone by the carbon due to chemical and heat treatment during nickel deposition [7].

Influence of $\mathbf{p H}$. The influence of varying $\mathrm{pH}$ over the distribution coefficient values for both $\mathrm{Cd}$ (II) and $\mathrm{Cu}(\mathrm{II})$ sorption has been studied and presented in Fig. 5.

The above graph is a clear indication of the fact that nickel coated carbon proves itself to be a good adsorbent even at low $\mathrm{pH}$ values specially in the case of $\mathrm{Cu}$ (II). The highest $\mathrm{R}_{\mathrm{d}}$ obtained for $\mathrm{Cu}$ (II) is at $\mathrm{pH} 4$ and comparable values obtained at $\mathrm{pH} 3$ and 5. However for Cd (II) the highest value of $R_{d}$ is observed at and around the neutral $\mathrm{pH}$ nonetheless, even at $\mathrm{pH} 5$ the $\mathrm{R}_{\mathrm{d}}$ is in a reasonable range.

Effect of Acids. Acids are an integral part of the usual industrial effluents and waste water carriers. If the adsorbent in use is not able to sorb in the presence of acids, it is not expected that it will help in the removal process of the toxic metals. 


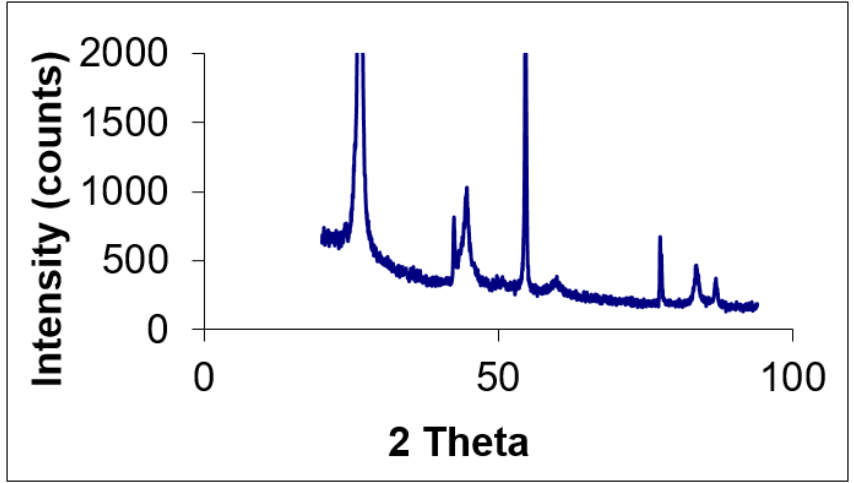

Fig. 1. XRD spectrum of nickel coated carbon.

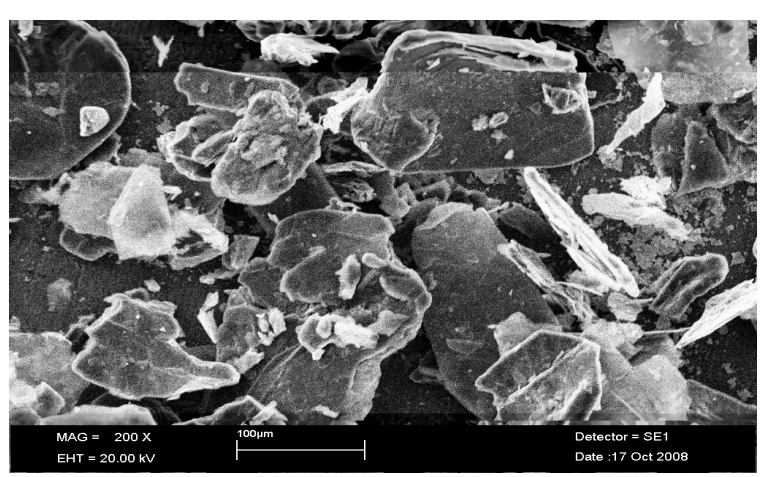

Fig.3. SEM surface micrograph of carbon.

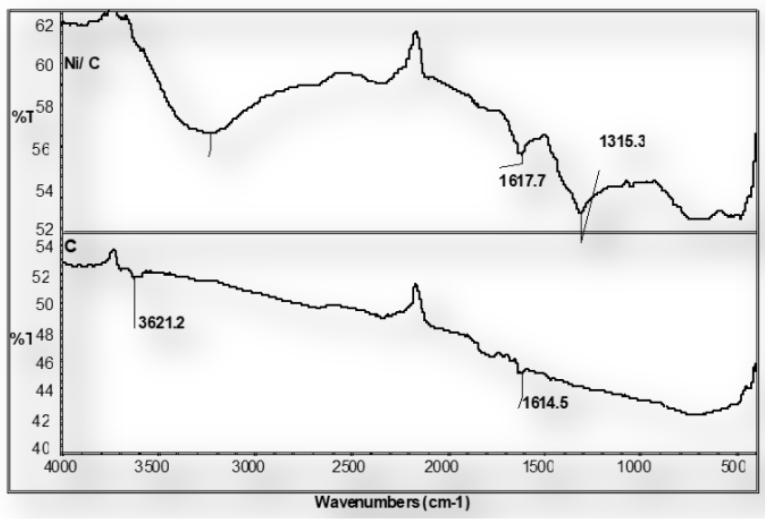

Fig. 2. Stacked FTIR plots of carbon and nickel coated carbon.

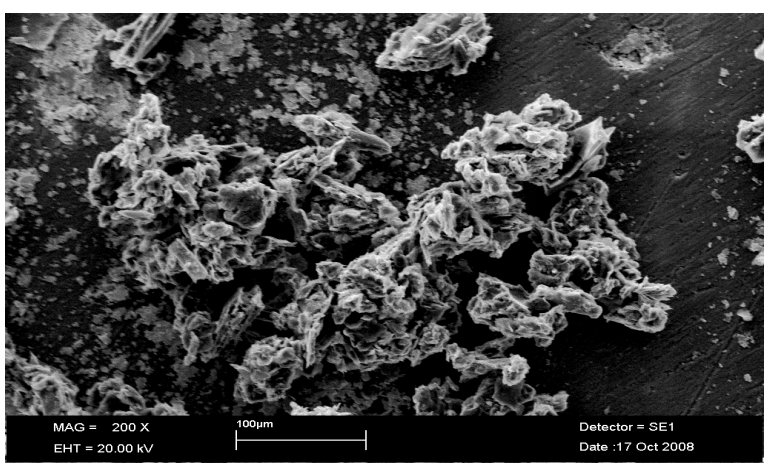

Fig. 4. SEM surface micrograph of nickelcoatedcarbon.

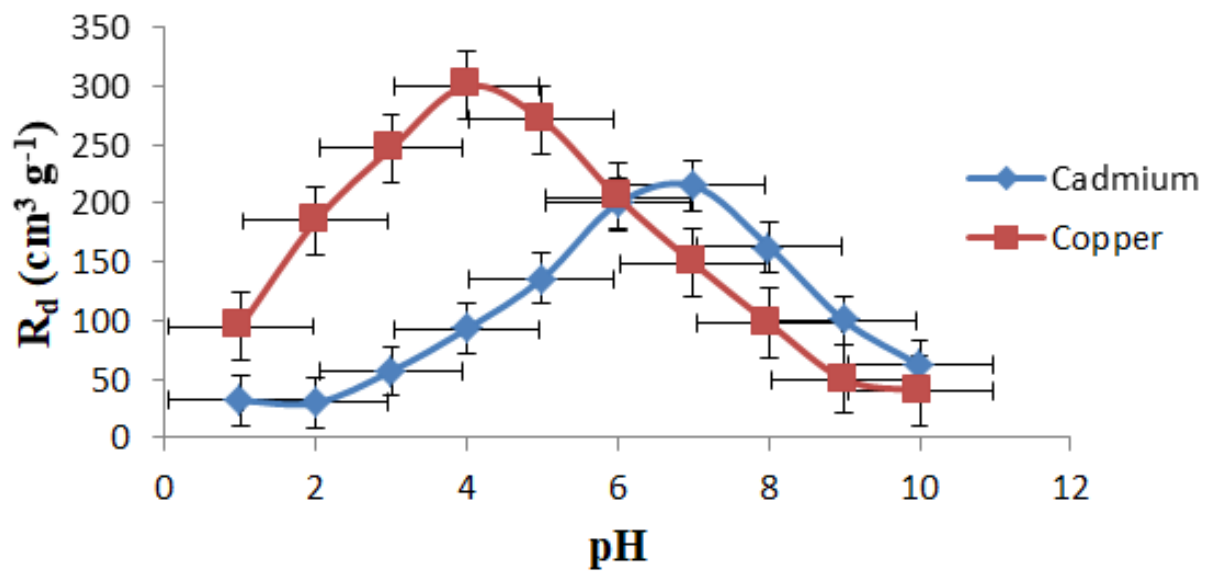

Fig. 5. Effect of sorptive medium's pH on the sorption of $\mathrm{Cu}(\mathrm{II})$ and $\mathrm{Cd}(\mathrm{II})$ onto the nickel-coated carbon.

Generally, if the trend is followed through this table it is observed that for each acid, i.e. hydrochloric, nitric and Perchloric, the highest $R_{d}$ value is depicted by the lowest concentration of the particular acid. Out of all the acids used as supportive media, Perchloric acid is the one giving better $\mathrm{R}_{\mathrm{d}}$ values for the sorption of $\mathrm{Cd}$ (II) and $\mathrm{Cu}$ (II). Implying that nano nickel coated carbon can be used as an adsorbent for heavy metals removals even if the waste water is contaminated with strong acids.

Kinetic Models. Three kinetic models have been applied to the sorption of Cd (II) and Cu (II) on nano nickel coated carbon. Applying Morris-Weber equation to find out the diffusion rate constants which govern the rate of approach of the sorbent molecules onto the sorbent and their subsequent diffusion before sorption; following equation is utilized [8] 


$$
q_{t}=K_{d} t^{1 / 2}+I
$$

Intra-particle diffusion rate constant is given by $\mathrm{K}_{\mathrm{d}}$. The numerical value of $I$ gives a direct idea about the boundary layer thickness. This means that smaller values of intercept implies to the smaller boundary layer effect and larger value gives the greater effect.

Table 1. Effect of various concentrations of different acids on the sorption of Cd (II) and $\mathrm{Cu}$ (II) onto the nano nickel coated carbon.

\begin{tabular}{|c|c|c|c|c|}
\hline \multirow{2}{*}{ S. No. } & \multirow{2}{*}{$\begin{array}{l}\text { Sorptive } \\
\text { Medium }\end{array}$} & \multirow{2}{*}{$\begin{array}{l}\text { Conc. of Sorptive } \\
\text { Medium (M) }\end{array}$} & \multicolumn{2}{|c|}{$R_{d}\left(\mathrm{~cm}^{3} \cdot \mathrm{g}^{-1}\right)$} \\
\hline & & & Cd (II) & $\mathrm{Cu}$ (II) \\
\hline \multirow{3}{*}{1.} & \multirow{3}{*}{$\mathrm{HCl}$} & 0.001 & $187 \pm 1$ & $197 \pm 2$ \\
\hline & & 0.01 & $135 \pm 1$ & $175 \pm 1$ \\
\hline & & 0.1 & $112 \pm 1$ & $112 \pm 1$ \\
\hline \multirow{3}{*}{2.} & \multirow{3}{*}{$\mathrm{HNO}_{3}$} & 0.001 & $209 \pm 3$ & $259 \pm 3$ \\
\hline & & 0.01 & $178 \pm 2$ & $228 \pm 3$ \\
\hline & & 0.1 & $196 \pm 2$ & $196 \pm 2$ \\
\hline \multirow{3}{*}{3.} & \multirow{3}{*}{$\mathrm{HClO}_{4}$} & 0.001 & $217 \pm 2$ & $269 \pm 2$ \\
\hline & & 0.01 & $193 \pm 2$ & $253 \pm 3$ \\
\hline & & 0.1 & $156 \pm 2$ & $213 \pm 3$ \\
\hline 4. & De-ionized water & - & $232 \pm 1$ & $245 \pm 3$ \\
\hline
\end{tabular}

The diffusion rate constant $\mathrm{K}_{\mathrm{d}}$ as calculated from Fig. 6 for $\mathrm{CD}$ (II) is given as $(5.39 \pm 0.25) 10^{-8}$ for $\mathrm{Cu}$ (II) it is, $(9.66 \pm 2.75) \cdot 10^{-8} \mathrm{~cm}^{3 \cdot} \mathrm{g}^{-1 \cdot} \mathrm{min}^{-1 / 2}$.

Lagergren plot (Eq. 3) is drawn for $\ln (1-\mathrm{F})$ vs. time, where $\mathrm{F}$ is the ratio of adsorbed amount of $\mathrm{Cd}(\mathrm{II})$ and $\mathrm{Cu}$ (II) at any instant $\mathrm{q}_{\mathrm{t}}$, to that at equilibrium or optimum shaking time $\mathrm{q}_{\mathrm{e}}$ [9]. From Fig. 7 a straight line relationship is depicted for the sorption of $\mathrm{Cd}(\mathrm{II})$ and $\mathrm{Cu}$ (II) onto nickel coated carbon. From the slope of these straight lines, value of rate constant $\mathrm{k}$ is calculated.

$$
\operatorname{In}(1-F)=-k_{1} t
$$

The value of rate constant $\mathrm{k}$ for $\mathrm{Cd}$ (II) is $(1.86 \pm 0.01) 10^{-1}$ and $\mathrm{Cu}$ (II) is $(5.29 \pm 0.36) .10^{-1} \mathrm{~min}^{-1}$.

According to the following Reichenberg equation, by plotting Bt vs. time, (Fig. 8) it is indicated that film diffusion is not limiting step of the overall adsorption process kinetics [10].

$$
B t=-0.4977-\operatorname{In}(1-F)
$$

Adsorption Isotherms. The data for distribution coefficient values as a function of the concentration of nano nickel coated carbon is used to develop various isotherms, which would not only confirm the adsorption capacity and surface heterogeneity of the adsorbent but also the adsorption energies of the respective adsorption processes.

Langmuir isotherms (Fig. 9) have been developed according to Eq. 5 [11].

$$
C_{e} / C_{a d s}=1 / M b+C_{e} / M
$$

$\mathrm{C}_{\text {ads }}$ is the adsorbed amount $\left(\mathrm{mol} \cdot \mathrm{g}^{-1}\right)$ and $\mathrm{C}_{\mathrm{e}}$ is the equilibrium concentration ( $\mathrm{mol}^{-1}$ ) of ions $\mathrm{M}$ is a constant which represents the maximum adsorption at monolayer while the solute's binding energy is given by constant b related to the change in adsorption's enthalpy and varies with temperature.

$\mathrm{M}$ value for $\mathrm{Cd}(\mathrm{II})$ is $(16.3 \pm 8.8)^{\cdot} 10^{4}$ and for $\mathrm{Cu}$ (II) is $(154 \pm 5.93) \cdot 10^{3}$ The constant $\mathrm{b}$ for $\mathrm{Cd}$ (II) is $(8.88 \pm 4.8) 10^{4}$ and for $\mathrm{Cu}(\mathrm{II})$ is $(12.3 \pm 54.8) \cdot 10^{4} \mathrm{~L}^{\mathrm{mol}} \mathrm{mol}^{-1}$. Freundlich isotherm outlined by Eq. 6 is being depicted in Fig. 10 for both the metals [12]. 


$$
\log C_{a d s}=\log C_{m}+1 / n \log C_{e}
$$

$\mathrm{Xm}$ for $\mathrm{Cd}(\mathrm{II})$ is $17.9 \pm 0.8$ and for $\mathrm{Cu}(\mathrm{II})$ is $20.22 \pm 1.26 \mu \mathrm{mol} . \mathrm{g}^{-1}$. The sorption energy $\mathrm{E}$ for the sorption of $\mathrm{Cd}(\mathrm{II})$ is $14.84 \pm 0.19$ and for $\mathrm{Cu}(\mathrm{II})$ is $14.71 \pm 0 . \mathrm{kJ}^{\mathrm{mol}}{ }^{-1}$. The sorption energy confirms that adsorption phenomenon is chemisorption for both the ions.

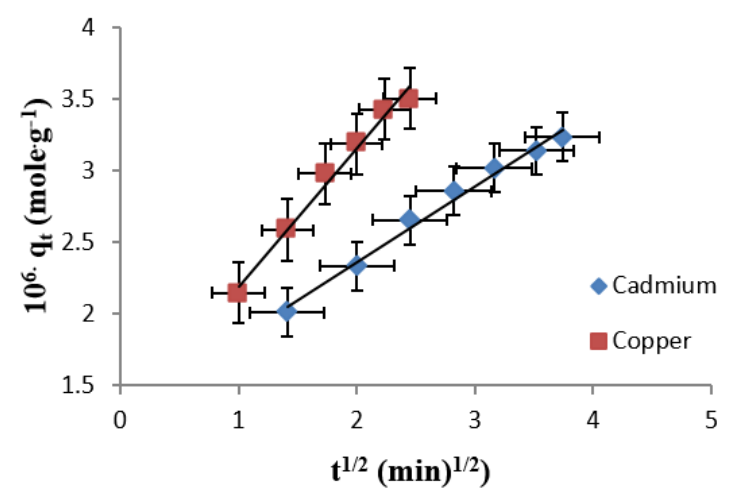

Fig. 6. Plot of $\mathrm{q}_{\mathrm{t}}$ vs. (time) $)^{1 / 2}$ for the sorption of Cd (II) and $\mathrm{Cu}(\mathrm{II})$ onto the nickel-coated carbon.

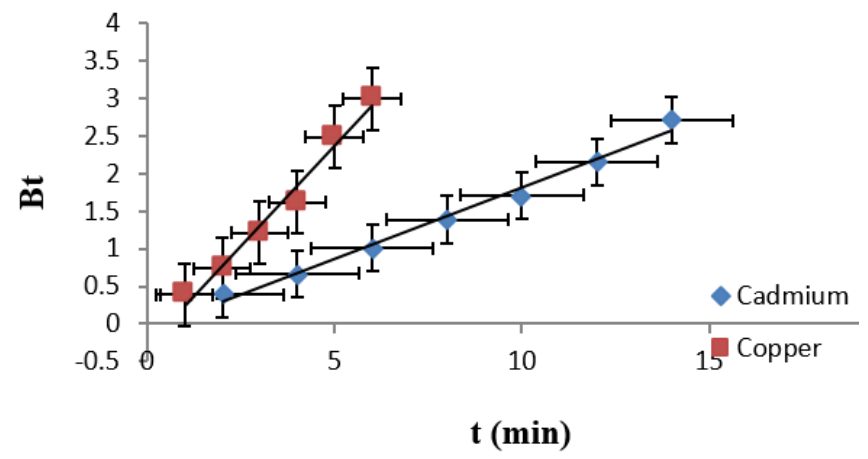

Fig. 8. Plot of Bt vs time for the sorption of $\mathrm{Cd}(\mathrm{II})$ and $\mathrm{Cu}$ (II) onto the nickel-coated carbon.

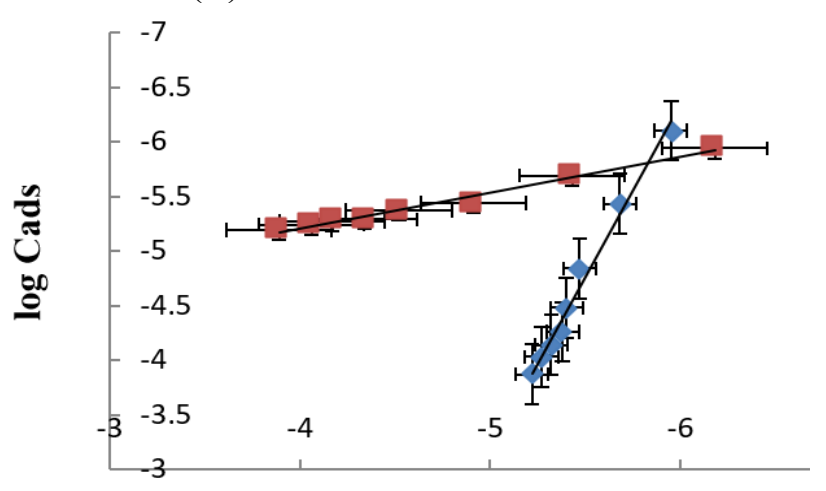

$\log$ Ceq

Fig. 10. Freundlich's isotherm for the sorption of $\mathrm{Cd}(\mathrm{II})$ and $\mathrm{Cu}$ (II) onto the nickel-coated carbon.

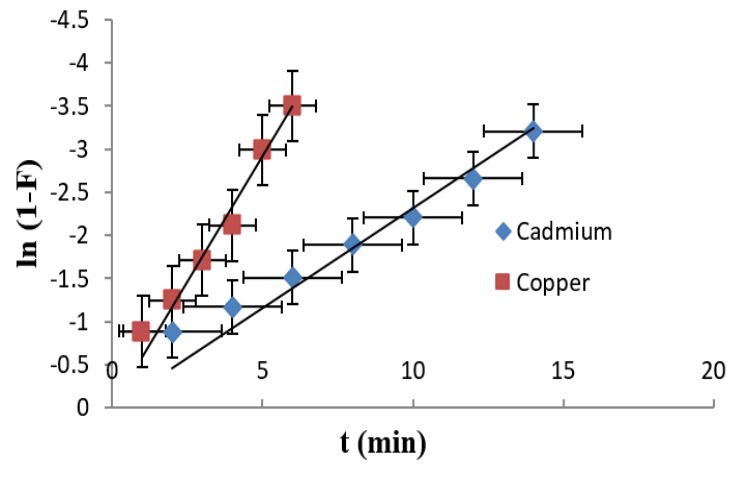

Fig. 7. Plot of $\ln (1-\mathrm{F})$ vs time for the sorption of $\mathrm{Cd}(\mathrm{II})$ and $\mathrm{Cu}$ (II) onto the nickel-coated carbon.

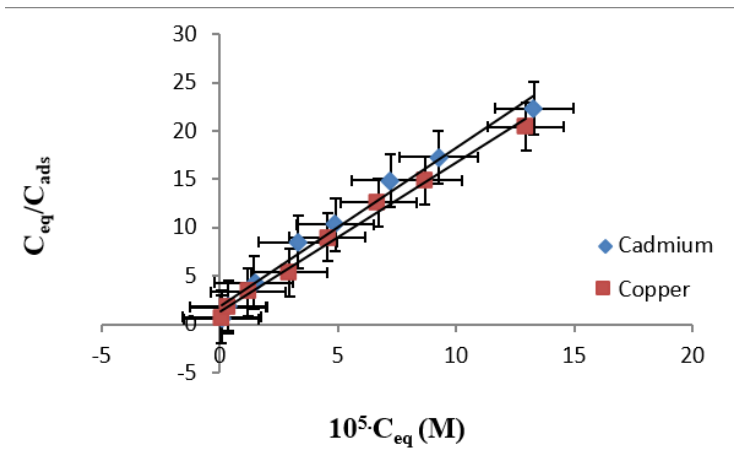

Fig. 9. Langmuir's isotherm for the sorption of $\mathrm{Cd}(\mathrm{II})$ and $\mathrm{Cu}$ (II) onto the nickel-coated carbon

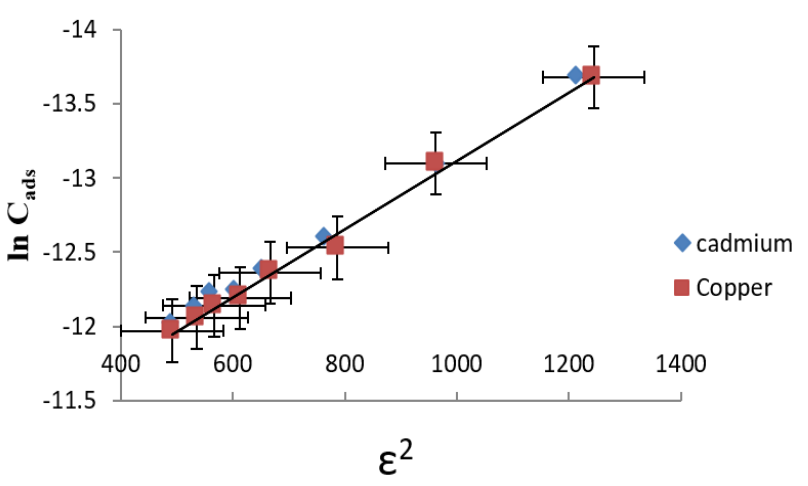

Fig. 11. The D-R Isotherm for the sorption of $\mathrm{Cd}(\mathrm{II})$ and $\mathrm{Cu}$ (II) onto the nickel-coated carbon.

Values of $1 / \mathrm{n}$ and $\mathrm{Cm}$ specify heterogeneity of the sorbent surface and its adsorption capacity respectively. $1 / \mathrm{n}$ for $\mathrm{Cd}(\mathrm{II})$ is $0.44 \pm 0.01$ and $\mathrm{Cu}$ (II) is $0.32 \pm 0.02$ while $\mathrm{Cm}$ for $\mathrm{Cd}$ (II) is $0.096 \pm 0.02$ and $\mathrm{Cu}(\mathrm{II})$ is $0.12 \pm 0.02 \mathrm{mmol} . \mathrm{g}^{-1}$.

Dubinin Radushkevich isotherm (D-R) is given by the following straight line equation [13].

$$
\ln C_{a d s}=\ln X_{m}-\beta \varepsilon^{2}
$$


Maximum sorption capacity is given by $\mathrm{X}_{\mathrm{m}}\left(\mathrm{mol}^{-1}\right), \mathrm{C}_{\mathrm{ads}}\left(\mathrm{mol}^{-1}\right)$ is amount of ions adsorbed per unit mass of the sorbent, a constant $\beta\left(\mathrm{kJ}^{2} \cdot \mathrm{mol}^{-2}\right)$ related to the adsorption energy and $\varepsilon$ is the Polannyi potential for adsorption given as:

$$
\varepsilon=R \cdot \ln \left(1+1 / C_{e q}\right)
$$

with gas constant $\mathrm{R}\left(\mathrm{kJ}^{\prime} \mathrm{mol}^{-1}\right)$, temperature $\mathrm{T}(\mathrm{K})$ and $\mathrm{C}_{\mathrm{e}}$ with usual significance. The sorption energy can also be calculated from this isotherm as follows:

$$
E=1 / \sqrt{-2 \beta}
$$

Thermodynamic Parameters. The thermodynamic parameters can be evaluated by:

$$
\log K_{c}=-\Delta H / 2.303 R T+\Delta S / 2.303 R
$$

The $\log \mathrm{K}_{\mathrm{c}}$ vs. 1/T plots (Fig. 12) furnish straight lines for both the sorbents; $\mathrm{K}_{\mathrm{c}}$ being the equilibrium constant and given as $\mathrm{K}_{\mathrm{c}}=\mathrm{F} /(1-\mathrm{F})$ with $\mathrm{F}$ representing fraction of the sorbed ions. Increase of sorption with temperature may be attributed to acceleration of the steps including creation of more active sites and enhanced diffusion of the sorbate species [7]. The change in enthalpy $\Delta \mathrm{H}$ for $\mathrm{Cd}(\mathrm{II})$ is $40.74 \pm 1.34$ and for $\mathrm{Cu}(\mathrm{II})$ is $34.04 \pm 0.85 \mathrm{~kJ}^{-1} \mathrm{~mol}^{-1}$. The change in entropy $\Delta \mathrm{S}$ for $\mathrm{Cd}(\mathrm{II})$ is $144.3 \pm 4.50$ and for $\mathrm{Cu}(\mathrm{II})$ is $122.90 \pm 2.85 \mathrm{~J} . \mathrm{mol}^{-1} \cdot \mathrm{K}^{-1}$.

\section{Conclusion}

Nano nickel coated carbon is not deteriorated under various $\mathrm{pH}$ conditions and acid concentrations, therefore it is safely concluded that the removal of heavy metals such as Cd (II) and $\mathrm{Cu}$ (II) can be brought about in the real waste water streams without any pre conditions. The positive values of change in enthalpy and change in entropy as discussed in the section, thermodynamic parameters depict an entropy driven process thereby confirming the feasibility of this removal. The values of sorption energies as calculated by $\mathrm{D}-\mathrm{R}$ isotherm for both the ions exceed the limit of $8 \mathrm{~kJ} \mathrm{~mol}^{-1}$ therefore this adsorption is chemisorption in nature and hence the process cannot be reversed under fluctuating physical conditions of temperature and $\mathrm{pH}$.

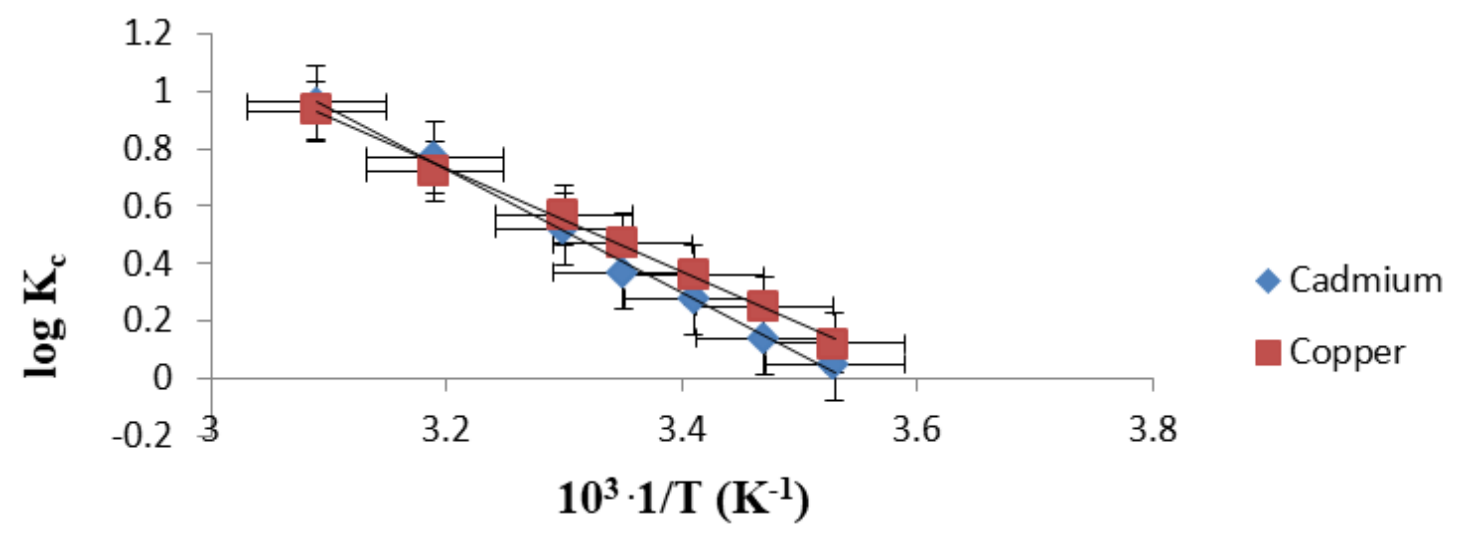

Fig. 12. Plot of $\log \mathrm{K}_{\mathrm{c}}$ vs. $1 / \mathrm{T}$ for the sorption of $\mathrm{Cd}(\mathrm{II})$ onto the nickle-coated carbon.

\section{References}

[1] M. Jaishankar, T. Tseten, N. Anbalagan, B. B. Mathew, K. N. Beeregowda, Toxicity, mechanism and health effects of some heavy metals, Interdisc. Toxicol., 7 (2014) 60-72.

[2] S. Martin, W. Griswold, Human health effects of heavy metals, Environ. Sci. Tech. Briefs for Citizens., 15 (2009) 1-6.

[3] B. Ashish, K. Neeti, and K. Himanshu, Copper toxicity: a comprehensive study, Res. J. Recent Sci., 2 (2013) 58-67. 
[4] K. Saravu, J. Jose, M. N. Bhat, B. Jimmy, B.A. Shastry, Acute ingestion of copper sulphate: A review on its clinical manifestations and management, Res. S. E. (2007) 74-80. http:// www.ijccm.org/text.asp 2007/11/2/74/33389

[5] R. Rahimzadeh, M. R. Rahimzadeh, S. Kazemi, A. Moghadamnia, Cadmium toxicity and treatment: An update, Caspian J. Intern. Med., 8 (2017) 135-145.

[6] L. Monser, N. Adhoum, Modified activated carbon for the removal of copper, zinc, chromium and cyanide from wastewater, Sep. Purif. Technol., 26 (2002) 137-146.

[7] T. Asim, R. Ahmed, M. S. Ansari, Preparation and characterization of carbon supported nanonickel and Its sorption behavior for zinc from aqueous solutions, Key Eng. Mater., 510 (2012) 271276

[8] W. J. Weber, J. C. Morris, Kinetics of adsorption on carbon from solution, J. Sanit. Eng. Div, ASCE, (SA2) 89 (1963) 31-60.

[9] S. Lagergren, Zur theorie der sogenannten adsorption gelöster stoffe. K. Sven. Vetenskapsakad. Handl., Band 24 (1898) 1-39.

[10] D. Reichenberg, Properties of ion-exchange resins in relation to their structure. III. Kinetics of exchange, J. Am. Chem. Soc., 75 (1953) 589-597.

[11] I. Langmuir, The adsorption of gases on plane surfaces of glass, mica and platinum, J. Am. Chem. Soc., 40 (1918) 1361-1403.

[12] H. Freundlich, H. S. Hatfield, Colloid and Capillary Chemistry. Methuen and co. Ltd. London, 1926.

[13] M. M. Dubinin, L. V. Radushkevich, Equation of the characteristic curve of activated charcoal, Chem. Zentr., 1 (1947) 875. 